\title{
Presentación
}

\section{EL TEATRO BARROCO EN SU CONTEXTO}

Mucho se ha debatido acerca del concepto de barroco, desde aquellos críticos que han insistido en considerarlo como una marca de estilo -transhistórico y transcultural- susceptible de presentarse de manera frecuente en diversas fases de la historia humana o como un término que sirve para designar conceptos morfológicos o estilísticos repetibles en culturas apartadas en el tiempo y el espacio. Tales acercamientos no hacen más que entregar una mirada sesgada y reduccionista del fenómeno barroco, que deja de lado su enorme multiplicidad y riqueza, y que trae como consecuencia la necesidad de otorgarle un contenido histórico específico. En ese sentido, cobran fuerza estudios ya clásicos que entienden el Barroco como un concepto de época, esto es, un periodo definido en la historia de algunos países europeos y americanos, en donde los más diversos campos de la cultura actúan como factores de una situación histórica determinada, la afectan y establecen vínculos entre ellos mismos. Así lo expresaba José Antonio Maravall en La cultura del Barroco: "Es decir, la pintura barroca, la economía barroca, el arte de la guerra barroco, no es que tenga semejanzas entre sí [...], sino que, dado que se desenvuelven en una misma situación, bajo la acción de unas mismas condiciones, respondiendo a unas mismas necesidades vitales, sufriendo una innegable influencia modificadora por parte de los otros factores, cada uno de estos resulta así alterado, en dependencia, pues, del conjunto de la época" (28-29). Dichas palabras intentan aunar criterios y construir una base sobre la que se sustente este "fenómeno inscrito en la serie de las diversas manifestaciones del Barroco europeo, cada una de ellas diferente de las demás y todas ellas subsumibles bajo la única y general categoría histórica de «cultura del Barroco»" (15).

En este complejo sistema de relaciones e influencias recíprocas cobra gran relevancia el arte barroco, especialmente, su teatro, "arte de masas" por excelencia, y uno de los principales divertimentos de la sociedad europea del siglo XVII. En España y de la mano de uno de sus más insignes ingenios, 
Lope de Vega, se desarrolla la Comedia Nueva, que desde sus primeras manifestaciones en los corrales de comedias, pasando por el teatro religioso y hasta llegar al gran teatro cortesano, supo aunar al más variado tipo de público, ya fuera masivo y popular o más restringido y culto; diversos y definidos espacios de representación escénica, ya fueran estos los patios y corrales o los coliseos y teatro cortesanos, los que a su vez delimitaban las posibilidades escenográficas (tramoyas, vestuarios, etc.) y tienen un papel clave tanto en el texto dramático como en su puesta en escena; diversas circunstancias de representación; géneros y subgéneros a los que se adscriben las obras, en la medida en que estos definen los tipos de personajes, sus acciones, su registro lingüístico, el tratamiento del decoro, los temas, las tramas y los efectos estéticos buscados en los espectadores.

Los estudios que aquí se presentan son una pequeña muestra de la diversidad de géneros, emisores, receptores, espacios, escenarios, temas, tópicos, entre otros aspectos, presentes en el desarrollo del teatro barroco. El primero de ellos, a cargo de Ignacio Arellano y titulado "Comedias melancólicas del Siglo de Oro: medicina, psicología y teatro", analiza la función que cumple la melancolía en tres piezas teatrales - La gitana melancólica, atribuida a Gaspar de Aguilar, El príncipe melancólico, atribuido alguna vez a Lope de Vega, y El melancólico de Tirso de Molina- y se explicita la importancia que tiene la afección melancólica en varios ámbitos del Siglo de Oro, por ejemplo en tratados médicos, políticos y filosóficos. Frente a esto se hace presente el papel que desempeña en el teatro, en donde puede aparecer como una enfermedad o afección morbosa, o como un fingimiento que sirve para ocultar pasiones o configurar el enredo ingenioso. Dichas funciones dependerán de la perspectiva genérica que adopten las comedias; así, en el caso de las piezas dramáticas o trágicas suelen utilizar a la melancolía como una enfermedad, en cambio en los géneros cómicos o lúdicos la melancolía actuará como un mecanismo dramático que posibilita la consecución de los diversos objetivos de los personajes y el enredo característico. Para determinar con precisión la función que la melancolía actualiza en cada obra, será necesario, entonces, "analizar con cuidado las perspectivas de los agentes melancólicos o supuestamente melancólicos para percibir la seriedad o la burla de dicha condición".

En el siguiente artículo, "Agua pasada mueve molino: la (auto)reescritura bizantina, de Lope de Vega a Castillo Solórzano", de Daniel Fernández Rodríguez, se aprecia la extrema complejidad de la literatura barroca a la vez que se destacan dos procedimientos de composición conocidos y 
utilizados por los artistas y escritores de la época: la imitación y la emulación. Fernández Rodríguez analiza el caso particular de Castillo Solórzano y su profunda vinculación con Lope de Vega, no solo en los círculos literarios del momento, sino también en el "magisterio" del segundo sobre el primero. Así es como se revisa la influencia de la obra lopesca, ya sea mediante el modelo de la comedia bizantina La viuda, casada y doncella o de la novela Guzmán el Bravo (o de ambos géneros a la vez) en la narrativa de Alonso de Castillo Solórzano, sobre todo en dos de sus novelas: El bien hacer no se pierde (Noches de placer, 1631) y La ingratitud castigada (La quinta de Laura, 1649). Del mismo modo, el artículo pretende desvelar el intrincado proceso de reescritura y autoreescritura que lleva a cabo Solórzano en su novela La ingratitud castigada, en donde "reelabora materiales tomados no solo de las obras citadas, sino también de otros dos relatos suyos, La libertad merecida (Jornadas alegres, 1626) y Amor con amor se paga (Los alivios de Casandra, 1640), hasta componer un rico mosaico intertextual", evidencia de la posible unión y correspondencia entre los más variados géneros literarios.

En "El sueño de Ulises: la visión onírica en El mayor encanto, amor de Calderón", Ariel Núñez examina con suma claridad y profundidad "la representación literaria y el funcionamiento dramático de los sueños" en la obra del gran ingenio español. Para ello realiza una completa revisión de la utilización de los sueños presentes en algunas obras tempranas de Lope de Vega -Los hechos de Garcilaso de la Vega (1579-1583) o La imperial de Otón (c. 1598)- hasta llegar a su empleo por parte de Calderón en una amplia variedad genérica que abarca tanto la tragedia, el drama religioso, los autos sacramentales, el teatro cómico breve como el teatro de corte o palaciego. Esta revisión permite aseverar que "la profusa aparición del mundo onírico en la obra del autor sigue modalidades muy diversas: unas veces se desarrolla como motivo, temática o mecanismo teatral, y otras se despliega tropológicamente como metáfora, símbolo o alegoría". En el caso de la comedia cortesana El mayor encanto, amor, la visión onírica participa como el recurso dramático cardinal de la obra, en la medida en que es "imprescindible para comprender íntegramente la trayectoria y la configuración del personaje del guerrero griego [Ulises, protagonista de la historia] y la apropiación y resignificación del mito grecolatino [de Circe] efectuada por el autor". El empleo de este procedimiento en la primera comedia mitológica calderoniana determina y aporta una notable densificación tanto en la configuración de su protagonista como en la significación de la propia obra. 
El último artículo del dossier, "«Todo el mundo es un escenario»: estudio comparativo de los espacios teatrales en el Barroco español y en la escena isabelina", aporta una visión descriptiva conjunta de dos de las principales manifestaciones dramáticas del Renacimiento y el Barroco. Su autora, Paula Baldwin, se centra en la perspectiva espacial de ambas escenas, fijando, en primer lugar, la dimensión antropológica del espacio "que subyace a todo acontecimiento teatral". Ese primer acercamiento le sirve de base para examinar de manera detallada el contexto cultural dominante en España e Inglaterra durante los siglos XVI y XVII, centrándose en la ubicación y la arquitectura de los teatros públicos -los corrales de comedias de la Cruz y del Príncipe en Madrid y del teatro del Globo en Londres-, esto es, la materialidad de dichos espacios con la intención de "comprender mejor los mecanismos de configuración espacial" presentes en la estructuración de los textos dramáticos, en donde la palabra poética y performativa "logran producir la ilusión teatral que hace visible lo invisible al crear espacios imaginarios en el escenario, en un proceso colaborativo entre los actores y el público".

Los ensayos aquí reunidos no solo revelan cómo el arte barroco remite a un periodo complejo en la historia social, en donde una profunda crisis en los cimientos políticos, económicos y culturales permitió la creación de una de las mayores manifestaciones artísticas y literarias, el teatro; sino también la importancia y urgencia del estudio sistemático del teatro barroco en nuestras latitudes, con el fin de comprender y acercar el arte y la literatura del Siglo de Oro a nuestro presente, pues sus códigos, símbolos y lengua son también manifestaciones de nuestra propia cultura. Estos artículos son muestra de la vitalidad, modernidad y buena salud que goza la investigación actual en torno a la Comedia Nueva, a la vez que sirve de señuelo a las futuras generaciones de especialistas que, estoy segura, verán en el Siglo de Oro una fuente inagotable de conocimiento.

JÉSSICA CASTRO RIVAS

Coordinadora del dossier El teatro barroco en su contexto

Universidad de Chile jessicacastro@uchile.cl 